\title{
Role of GIS in Health Management Information System and Medical Plan: A Case Study of Gangtok area, Sikkim, India
}

\author{
Ashok Kumar Sharma ${ }^{1, *}$ \\ ${ }^{1}$ National Institute of Disaster Management, Ministry of Home Affairs, Govt. of India 110002, NEW DELHI-INDIA \\ Corresponding author* \\ Received 22 Dec 2014 \\ E-mail: ashok.nidm@gmail.com \\ Accepted 05 Jan 2015
}

\begin{abstract}
Geographical Information System (GIS) in a Health Management Information System (HMIS) can be a powerful tool to make health care delivery more effective and far more efficient. It includes database management, planning, risk service area mapping, location identification, etc. One of the causes for this sudden surge of GIS use in healthcare application is the spatial dependency of health related factors. The use of GIS helps capture, store, combine, analyze and display data using Remote Sensing, topographical surveys, urban survey and town planning, geology, hydrology, traffic and transport engineering, land use pattern, rainfall pattern, and drainage. (Mathew, 2005). In the research work use of GIS software ILWIS for assessing the social network and health services available in Gangtok area, East Sikkim. Mapping of essential resources like road networks, locate the health facility in the study area and find out the population density using GIS techniques.
\end{abstract}

Keywords: Sikkim, Mapping, Rainfall, Disaster

\section{Introduction}

The interaction between vulnerabilities and disaster hazards may result in significant injuries and the loss of human lives. Since a large number of casualties can easily overcome the existing but partly destroyed medical facilities, establishing an emergency health services is critical. The type of health services provided depends on whether the emergency situation is a natural disaster, a complex emergency or protracted refugee health; but it must guarantee basic physical and mental care as well as prevention. Health and human service troubles facing the world today exist in a geographic context and any analysis must consider this. Understanding the issues ranging from medical epidemiology to health care access requires a comprehensive understanding of their geography.

Medical preparedness plans for disasters, therefore, is significant and constitutes one of the most vital elements in disaster response. Medical preparedness plans focus on protecting resources for better utilization, lay down priorities for augmentation and provide an appropriate response in dealing with casualties.
Disasters affect health in many ways first, are the health problems related to the type of disasters. Earthquakes and landslides may have physical injuries, whereas floods may cause infections and water borne diseases. Thus, different types of disasters will have different types of health impact on the population.

Second, are the health problems, which could be connected to all types of calamities? Communicable diseases are known to go up in disasters irrespective of the character. The evaluation needs of the population are done by important affected population, identifying and anticipating needs and identifying potential secondary risks to health. This is managed through controlling the inherent risks, mental ability and capability of hospitals within the area, estimating the number of casualties both dead and injured and logistical support available. Pre-hospital and hospital plans for caring for casualties are all important in coordinating health services for disaster situations. The prehospital disaster plan focuses on search and rescue of victims requiring either specialized medical personnel as in the case of persons trapped in buildings collapsed by natural or manmade calamity. 


\section{The Study Area}

Gangtok, the capital city of Sikkim is located in the East district and lies between $27^{\circ} 17^{\prime} 20^{\prime \prime}$ to $27^{\circ} 21^{\prime} 47^{\prime \prime} \mathrm{N}$ latitude and $88^{\circ} 35^{\prime} 12^{\prime \prime}$ to $88^{\circ} 39^{\prime}$ 40 " E longitude (Fig 1). The topography of the study area is highly undulating with hills of 900 to 2400 meters above mean sea level. Gangtok is situated in the key part of the leaf shaped Rongni Chu catchment, surrounded by
Rani Khola in the West and the Rora Chu in the East. Gangtok is often wrapped in fog during the monsoon and in the wintertime months. During monsoon i.e. June to September month, the rain often causes landslides in the region. The total average rainfall of the study areas is 3500 $\mathrm{mm} /$ year (IMD Rainfall data). The minimum temperature is recorded in the month of January is $5.3^{\circ} \mathrm{C}$ and a maximum of $21^{\circ} \mathrm{C}$ in the month of June.

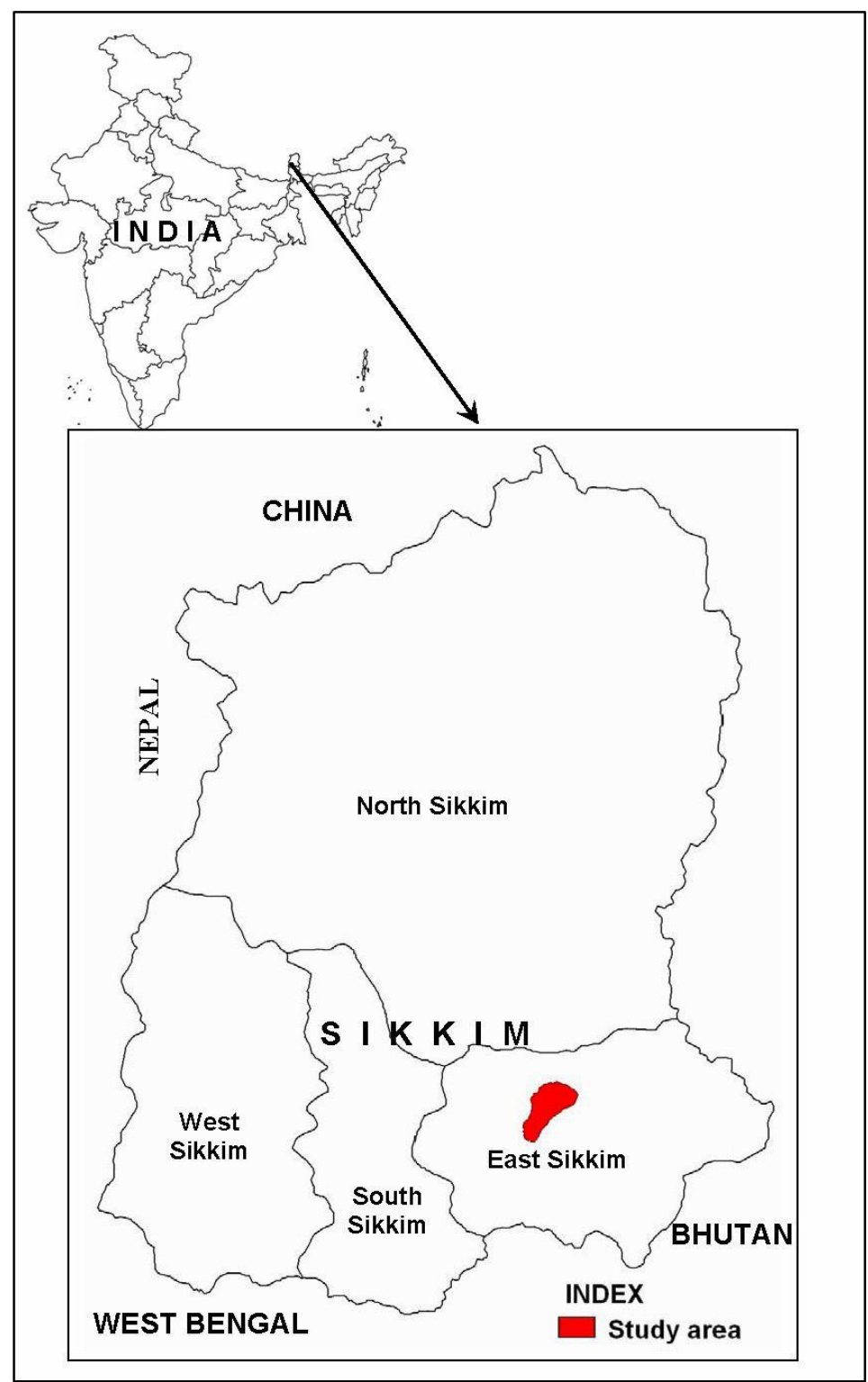

Fig 1. Location map of study area 


\section{Methodology}

Geographic Information System (GIS) provide as a common platform for the convergence of multi-disease surveillance activities. Public health resources, specific diseases and other health issues can be mapped in relation to their surroundings and existing health and community infrastructures. GIS helps to generate thematic maps that render the intensity of a disease (Najafabadi, 2009). GIS is a system composed of hardware and software to collect, process, analyzes data like tabular and spatial to produce geographic based information in order to improve decision making. In the public health domain, GIS methods were mostly used for occurrence analysis and epidemiologic studies (Fuad, et al., 2006). GIS aids in faster and better health mapping and analysis than the conventional methods.

Using GIS, helps those working in the health industry manage their information to make better decision. By tying information to specific locations, including hospital and surgeries, contaminated land and spread of disease, analysts can produce maps that help them identify patterns and understand relationships. GIS provides a common analytical framework within which health authorities can understand problems and formulate responses, improving incident management and health planning. GIS is becoming a vital tool in healthcare applications. It includes database management, planning, risk service area mapping and location identification, etc. GIS helps to generate thematic maps that depict the intensity of a disease or vector. It can create buffer zones around selected features and then combine this information with disease incidence data to determine how many cases fall within the buffer. It can also map the impact zone of the vector propagation site, where control activity needs to be strengthened. GIS can identify catchment areas of health centers and also locate suitable sites for a new health facility.

\section{GIS Technology For Human Services}

Geographic Information System technology provides a visually powerful opportunity for human service societies to analyze social services in relation to its clients and to the communities in which they operate.
Knowledge of where people live and work and its relationship with other community parameters such as socioeconomic profile, existence of health facilities and schools, etc., is a powerful analytical tool for planning human service delivery to needy clients. By mapping the location of problems of concern in specific localities, human service agencies can develop service strategies that are sensitive to community needs. GIS helps human service societies to produce meaningful and attention maps, which visually highlight important administrative, policy and practice issues and uncover new insights such as gaps in service delivery and location of facilities in an area of new demand for services.

The geographical investigation of environmental health hazards encompasses a wide range of studies in which GIS plays a useful role, including studies of reported disease clusters, geographical surveillance, analysis of health statistics in relation to single or multiple sources of pollution, natural calamities, chemical accidents, etc. It is also useful for modeling the distribution of exposures, as well as the size and characteristics of the population at risk. Modeling of different scenarios, such as, pollution dispersion from an accident, provides an indication of expected casualties and later health impacts. GIS has been used in health, particularly in the area of epidemiology and public health. So, GIS has been applied in a lot more health areas such as medical research, health insurance, health policy formulation, etc. Emergencies occur anywhere, at any location, at any time, and in various different ways - thus making any one of us susceptible. Although the structure of the Emergency Medical Care System differs across nations, the aims in applying emergency medical services are worldwide the same (Hussain and Jagadish, 2003).

- To save lives

- To limit damage to individual health

- To initiate recovery procedures ensuring the best possible quality of life Reacting to a public health emergency, such as the planned release of a biological agent, will require a certain level of infrastructure like transportation, hospital beds and medical countermeasures like, vaccines and other pharmaceuticals. 
An immediate response needs to plans take into explanation the likely flow of individuals into hospitals and other medical care centers and uncertainties regarding the scale and period of such a rush. In order to efficiently estimate the level of infrastructure required and the amount of medical countermeasures needed, health workers must have sufficient and logically perfect information about a given population. Demographic data and calculations, such as age of a population, sex ratio, and geographical dispersion are essential for formulating empirically-based preparedness plans. More specifically, using positive population projections and non-emergent morbidity rates in the creation of policy can help to ensure that there are sufficient drugs, devices, hospital beds, transport and care providers for a given population in the case of a public health emergency.

Remaining at the logistical stage, but going beyond simply the magnitude of infrastructure and countermeasures required, an effective preparedness plan must determine the appropriateness and estimated effectiveness of these necessities for any given group of individuals. Population level data can be used to evaluate the costs and benefits of preparedness policies and the development of particular levels and types of countermeasures and infrastructure (Allen and Katz, 2009).

\section{Public Health Mapping}

Mapping in easy terms could be said to be the representation of real life geographic features using organized symbols. The history of mapping has progressed from the era of representation on clay tablets to computer generated maps of today. The latter has evolved to what is now known as GIS (Tombari, 2009). GIS can integrate graphic information and data in databases to support the production of geographic information for further arrangement, analysis, and management. The role of the network analysis in the field of the spatial analysis is rapidly gaining momentum. In network analysis, the "optimum path" is derived by considering many criteria. Criteria could be the level of the road, one way or two way transportation, speed limit, etc.
Further, following the above information then giving the different priority will help arrive at the destination in the most efficient manner.

The Public Health Mapping is a user-friendly data management and mapping system customized specifically for public health users developed in Predicting Spatial. Public Health Mapping is basically a thematic mapping process. Develop spatial and non-spatial data, to identify low and high-risk, assist planning and implementation of control measures and monitoring and evaluation of control measures. Health administrators, professionals and researchers need training and user support in GIS technology, data and epidemiological methods in order to use the GIS properly and effectively.

Maps of health statistics can be invaluable in understanding local patterns of diseases and their geographical association. They have the advantage of conveying instant visual information accessible to non-experts, as well as, public health professionals. Even some other benefit of GIS is that it allows semi-automated information processing so that depth psychology can be borne out at high resolution and with extensive geographical coverage.

In many ways, GIS is an ideal tool for planning, organizational issues of health service. Firstly, referral patterns of the hospitals and emergency clinic locations to share with emergency situations are extremely suited to GIS analysis. Secondly, estimation of service areas of hospitals can be established. There are problems of accurate enumeration as the population serviced by a hospital is usually geographically dispersed, and not neatly constrained by administrative and census boundaries. However, it is frequently desirable to characterize the population that a hospital serves, so that proper explanation can be taken of its demands. Overlay of map layers- address locations on census boundaries, and other geographical features- using GIS techniques can help to define a hospital's service area.

Thirdly, that the primary, secondary, and tertiary health care services are accessible to all sections of the population, including those who have to rely on public transport to reach a health center, 
areas served by specific facilities and travel times are, therefore, important to service configuration and can be examined in the framework of location analysis of GIS. Social as well as physical factors can be brought into the analysis using area-based markers of socioeconomic deprivation, female-headed houses, and houses with physically challenged children, houses with senior citizens, etc.

\section{Health and Medical Preparedness}

Disaster medicine deals with the public health management of disasters. It addresses various topics, such as causality area management and hospital management through various schemes and activities. Medical preparedness, according to the Medical Preparedness for Disaster, implies local reinforcement of important medical care functions. It is invoked when available capacity is or can be expected to be insufficient for emergency care. Medical preparedness basically implies planning for medical and health related aspects for meeting disasters.

\section{Hospital in Gangtok}

In the capital of Sikkim, there is one state hospital that is Sir Tashi Namgyal Memorial (STNM) Hospital with strength of 300 beds and qualified doctors for all the special fields. A 500 bedded medical college hospital in collaboration with the Manipal Pal Foundation (Central Referral Hospital) is also functioning in the Gangtok area. There is one Ayurvedic Hospital and one Homeopathic Hospital, in these hospital there are no bed facility only OPD facilities available (Fig 2).

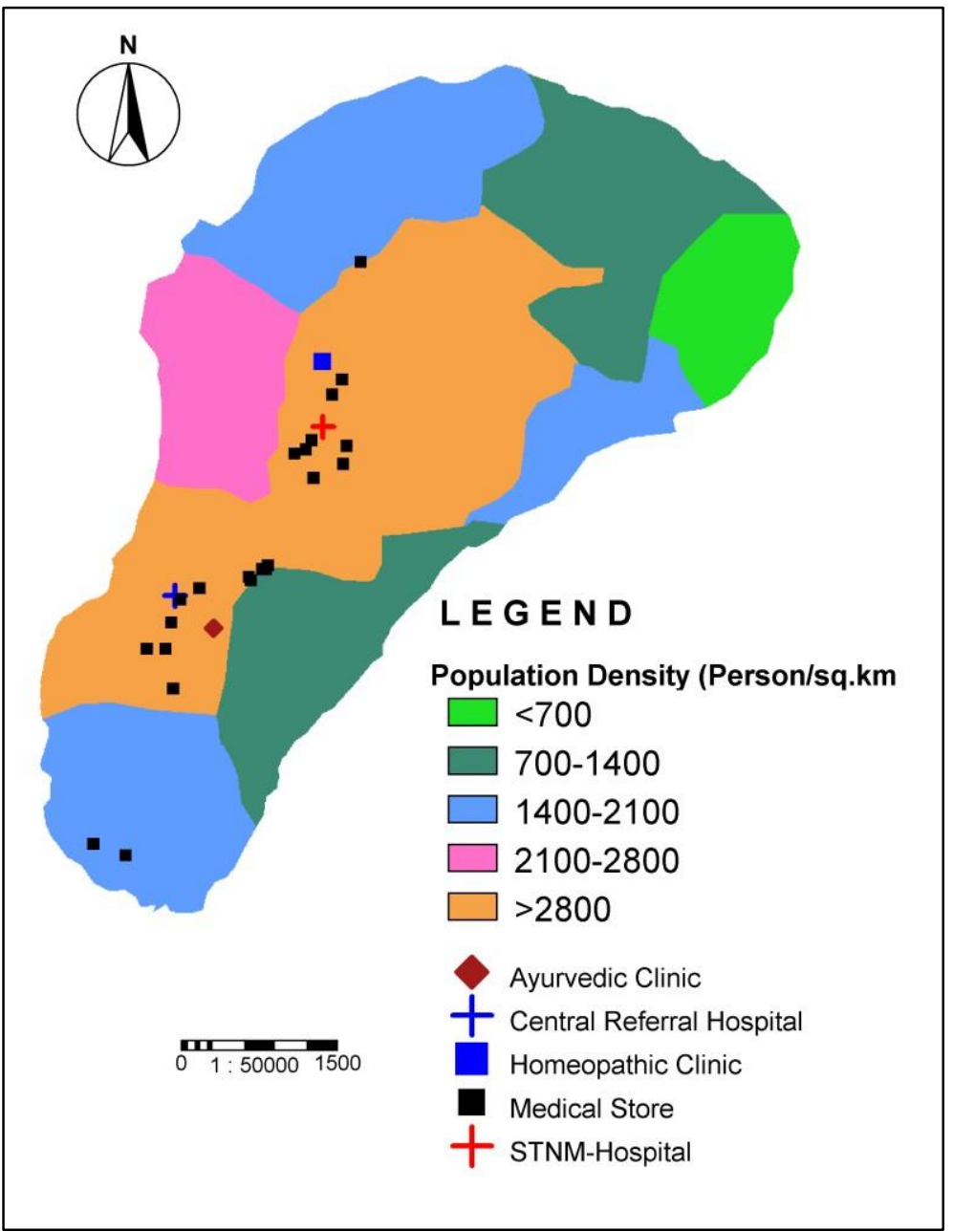

Fig 2: Health and Medical facility with population density in Gangtok area. 


\section{Population}

This area falls under the following revenue blocks - Penlong, Burtuk, Sichey, Chandmari, Rongyek, Gangtok (includes Rajbhavan), Tathangchen, Tadong, Syari and Samdur. The total Population of Gangtok area as per census 2011 is 98658 and population density details in figure 2 .

\section{Road and Transportation}

Gangtok, as other cities in India, is experiencing rapid growth of traffic caused by increase in motor vehicle usage. Severe congestion is being experienced in the central area of the city specially M.G. Road, Denzong Cinema Road, Deorali Road, North Sikkim Highway, Naya Bazaar Road and Tibet Road. Gangtok has become a very popular tourist destination in the North East attracting mostly domestic as well as foreign tourists, which has put extra load on transport network of the city. National High Way $31 \mathrm{~A}(\mathrm{NH})$ is the main road transport link connecting Gangtok with other parts of the state (Figure 3). Gangtok is connected by National Highway (NH 31-A) to Siliguri, which is a major town in the North of West Bengal.

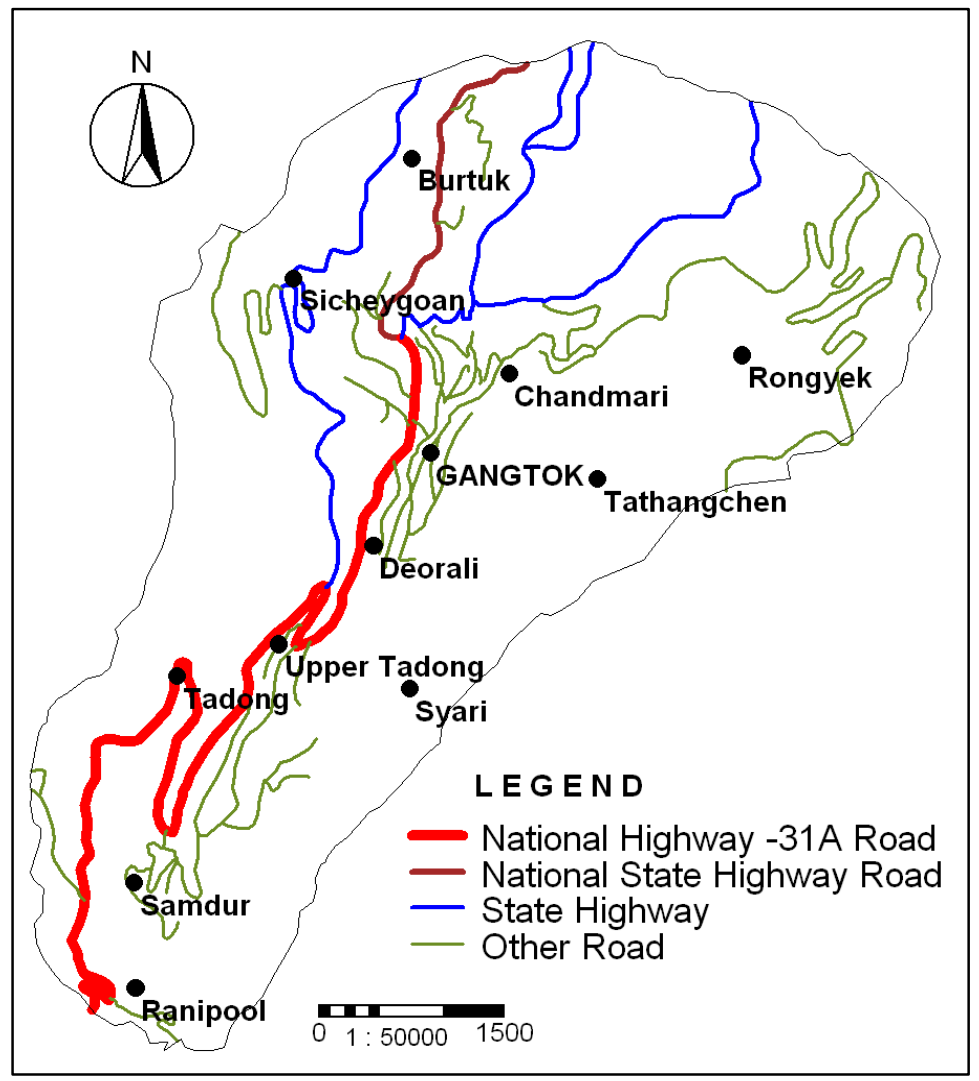

Fig 3. Road network in Gangtok area.

\section{Health Management Information Systems}

At district level and less there are no same structures, which can ensure the quality reporting. Physical data collection, analysis and inadequate manpower are two major constraints in developing the state of the facility Health Management Information System.

Telemedicine investigation, monitoring, and management of patients, and also the education of patients and staff using systems that allow ready access to expert advice and patient information, no matter where the patient or relevant information is located. Through telemedicine super specialty health care centers or specialists are connected through the Internet, and expert opinion is sought by sending the required data and relevant information about a health problem through Internet from any part of 
the world. The process is fast, cost effective, and time saving.

\section{Medical Preparedness in Disasters}

Disaster causes disturbance to the human, social, economic and ecological life of the society. Its causes disturbance, death, damage, devastation, disability, epidemic, diversion of resources and immense burden to the exchequer. The Medical Preparedness for Disasters, define disaster as a situation in which the need of medical care exceeds the immediately available resources, and in which extraordinary and coordinating measures are necessary, if normal quality standards are to be maintained. Medical preparedness, according to the Medical Preparedness for Disasters, implies local strengthening of vital medical care functions. It is invoked when available capacity is or can be expected to be insufficient for emergency care. Medical preparedness basically implies planning for medical and health related aspects for strike disasters.
Disasters which are small in shapes and sizes impact a small number of people and put intense demands on the health system for a short period, while other wide disasters may involve a large number of casualties, but reach a plateau only after a latent period, placing heavy continuing demands on the health system. Medical preparedness plans for disasters, thus, are important and constitute one of the most vital elements in disaster response. Medical preparedness plans for the protecting resources for optimal utilization, give up priorities to increase and provide an appropriate response in dealing with casualties.

Planning for the remote areas is necessary as these areas have a scarcity of resources in terms of men, material, money and other facilities such as hospitals, infrastructure, communication, etc. The trained manpower has to be sent to undertake the survey of the area, conduct triage, treat casualties, and transport the affected and sending the casualties to the hospitals for treatment and specialist care (Fig 4).

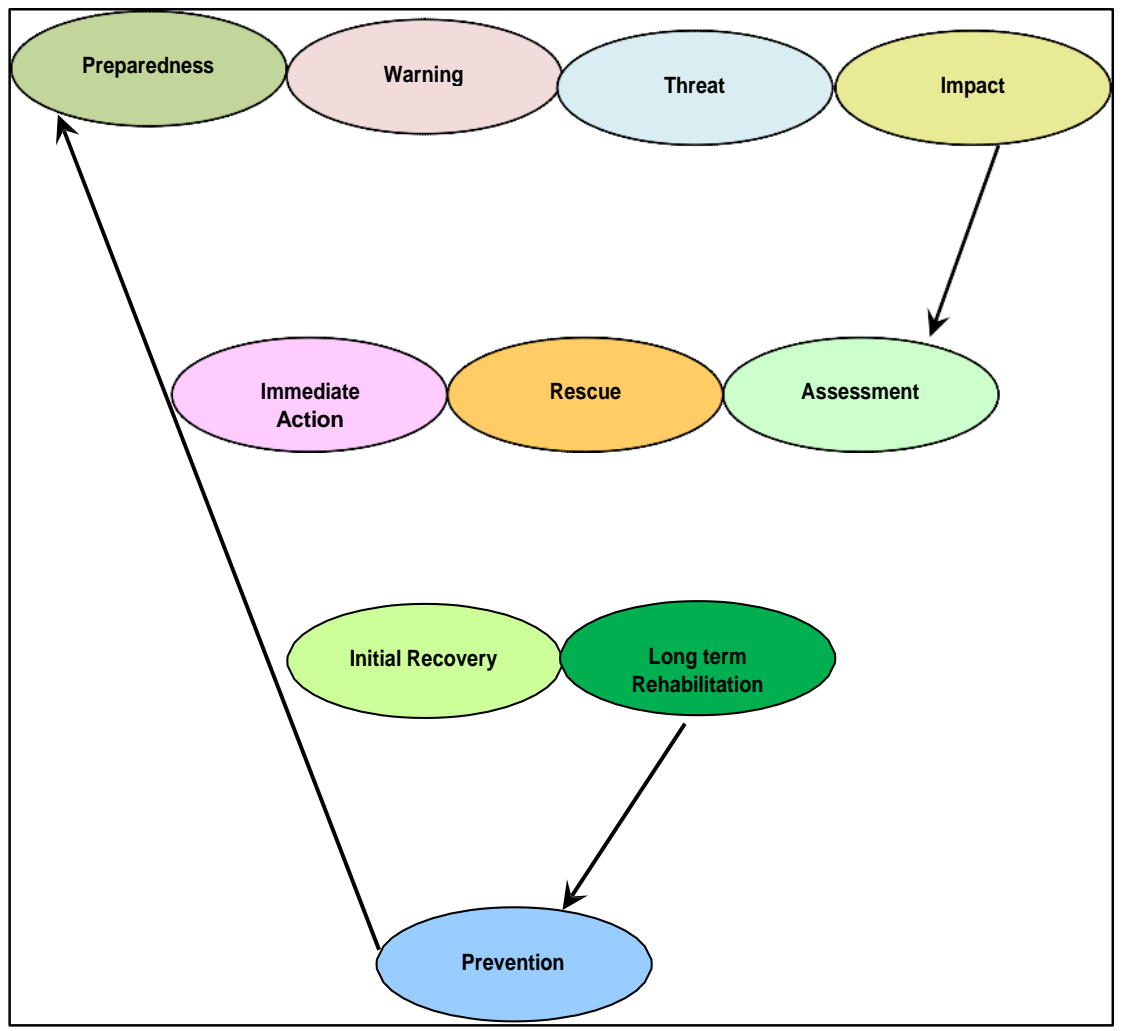

Fig 4. Medical care of mass casualties in Disaster. 


\section{Conclusions}

Sikkim, a small state in the Eastern Himalayas has shown, in recent times an obvious increase in the total registered deaths of an emergent nature, in the form of cardiovascular, accident and other emergency situations. Available data indicate that trauma has grown to become the number one cause of death in the most productive age group with the annual accident rate surpassing that of the developed countries. While factors contributing to this increase could be as diverse as rapid urbanization, sociodemographic and epidemiological transition and the largely rough and hilly terrain, the major concern and issue is the health systems we have in place to take up the challenge. The existing system is at best, inadequate in terms of equipment and skilled manpower to deliver Emergency Medical Services.

STNM Hospital, the central referral institution of the state which provides Emergency Medical Care not only to the urban population of the state capital of Gangtok but also to most of the rural population of the rest of Sikkim. The alarming increase in the workload due to faster development and always rising vehicular traffic and frequent natural calamities calls for the need to expand the facilities. Compounding the problem of the lack of proper management facilities and prompt attention to emergency patients is the hilly terrain where invariably the only possible mode of transport is by road, which in the monsoon season is time and again breached, making transportation of patients a major problem.

This study was carried out to introduce the general position of the Gangtok area through the Health Information and Medical preparedness using GIS study.

For GIS analysis, several applications were used as:

$>$ Location of study area

$>$ Road network

$>$ Population density

$>$ Location of Hospital and Medical facilities

Health management requirements, information on a different phase like the occurrence of diseases, facilities that are available in arranging to take decisions on either creating infrastructure facilities for taking immediate action to handle the situation and quickly. Medical preparedness plan requires an integrated approach to disaster site management and clinical casualty management working in a coordinated technically. Medical and health services have a very essential role to play in disaster management. It is their first and primary responsibility to provide emergency care and save the life of people. Medical and health response assumes the top most priority in the entire task of disaster management.

GIS is an ideal tool for planning, organizational issues of health service. Firstly, referral patterns of the hospitals and emergency clinic locations to deal with emergency situations are highly suited to GIS analysis. Health management needs the monitoring of the health status of the population, the provision of services as to the coverage and utility, drugs stocks and consumption patterns, equipment status and availability, finances, personnel on a regular basis. Medical preparedness, according to the Medical Preparedness for Disaster, implies local reinforcement of important medical care functions. It is invoked when available capacity is or can be expected to be insufficient for emergency care. Medical preparedness basically implies planning for medical and health related aspects for meeting disasters.

\section{Acknowledgement}

I am heartily thankful to Dr. Satendra, IFS, Executive Director, National Institute of Disaster Management, New Delhi (Ministry of Home Affairs Govt. of India) for his kind support for writing this paper. I am very grateful to Dr. A. P. Krishna, Professor, Department of Remote Sensing, Birla Institute of Technology (BIT), Ranchi for guiding and sharing knowledge and techniques of Remote Sensing and GIS. I also happy to convey my deep thanks to Dr. Varun Joshi, Associate Professor, Guru Govind Singh Indraprashtha University, New Delhi for his kind encouragement for this work. 


\section{References}

Allen, H. and Katz, R. (2009). Demography and Public Health Emergency Preparedness: Making the Connection, Popul Res Policy Rev DOI 10.1007/s11113-009-9158-1,

Fuad, A., Kusnanto, H., Utarini, A., Dijk, J.P. Van and Groothoff, J.W. (2006). The use of geographic information systems (GIS) for rapid assessment of health facilities following a disaster: the case of the tsunami disaster in the province of Aceh.

Hussain Al-Harthei and Jagadish S. (2003). The use of GIS for the Emergency Medical Care System, EMCS, GISdevelopment.net --> Application --> Health.

Mathew, D. (2005). Information Technology and Public Health Management of Disasters- A Model for South Asian Countries,

Najafabadi, A.T, (2009). Applications of GIS in Health Sciences, Shiraz E Medical Journal, Vol. 10, No. 4. Springer.

Tombari Sibe, R (2009). Challenges of Mapping Applications in Health and Academic Research in the underdeveloped World - Case Study of The Niger Delta Region (Nigeria), GISdevelopment.net --> Application --> Health. 